\title{
Deixadas para trás: sentimentos vivenciados por esposas de emigrantes submetidas ao isolamento conjugal
}

\section{Left back: feelings lived by wives of emigrants submitted to the matrimonial isolation}

\author{
Odacyr Roberth Moura da Silva ${ }^{1}$, Ana Paula de Freitas Mendonça Machado ${ }^{2}$, Carlos \\ Alberto Dias ${ }^{3}$
}

Resumo

\begin{abstract}
A emigração internacional em Governador Valadares e região, iniciada na década de 1960, cujo ápice se deu na de 1980, continua como importante processo de deslocamento populacional, apesar das políticas restritivas impostas pelos Estados Unidos. Até a década de 1990, a emigração masculina cresceu consideravelmente, induzindo a formação de novas configurações familiares e novas maneiras de organização das rotinas diárias pelas parceiras que permaneceram no Brasil. O presente estudo investiga o sentimento de solidão vivenciado por mulheres de emigrantes submetidas ao isolamento conjugal decorrente da ida do parceiro para o exterior como emigrante. Trata-se de um levantamento no qual foram realizadas entrevistas domiciliares guiadas por um Roteiro Semiestruturado de Entrevista junto a 247 mulheres residentes na cidade de Governador Valadares/ MG. A amostra foi intencional, não probabilística, os dados de natureza quantitativa foram submetidos à análise descritiva, e os de natureza qualitativa (fragmentos dos discursos) à Análise de Conteúdo proposta por Bardin. Embora o projeto de emigrar seja construído pelo núcleo familiar e apoiado pela Cultura Migratória característica da região, há evidências de que as entrevistadas vivenciam considerável sofrimento psíquico, sugerindo que o processo emigratório traz implicações indesejáveis para todos os envolvidos.
\end{abstract}

Palavras-chaves: Emigração. Solidão. Mulheres de emigrantes. Isolamento conjugal.

\begin{abstract}
The international emigration in Governador Valadares and its region initiate in the 1960s, whose apex occurred in the 1980 s, it continues as important process of population displacement, in spite of the restrictive policies imposed by the United States. Until the 1990s, the masculine emigration grew considerably, inducing the formation of new family configurations and new ways of organization of the daily routines for the partners that stayed in Brazil. The present study investigates the feeling of solitude lived by wives of emigrants submitted to the matrimonial isolation due to the partner's leaving for exterior countries as emigrant. It is a fact finding in which home interviews were accomplished guided by a Semi-Structured Interview Guide with 247 women residents in Governador Valadares/MG city. The sample wasn't probabilistic, but intentional, the data of quantitative nature were submitted to the descriptive analysis, and the data of qualitative nature (fragments of the speeches) to the Analysis of Content proposed by Bardin. Although the plan to emigrate is formed by the family nucleus and leaning by the characteristic Migratory Culture of the region, there are evidences that the interviewees live considerable psychic suffering, suggesting that the emigration process brings undesirable implications for all of them that are involved.
\end{abstract}

keywords: Emigration. Solitude. Wives of emigrants. Matrimonial isolation.

\footnotetext{
${ }^{1}$ Mestrando em Psicologia pela Universidade Federal do Espírito Santo - UFES. Psicólogo pela Universidade Vale do Rio Doce UNIVALE. Pedagogo pela Universidade de Uberaba - UNIUBE.

${ }^{2}$ Psicóloga, graduada pela Universidade Vale do Rio Doce - UNIVALE. Especializando em Neuropsicologia pelo Instituto Brasileiro de Neuropsicologia e Ciências Cognitivas - IBNeuro.

${ }^{3}$ Doutor em Psicologia Clínica com experiência em docência em instituições de ensino nacionais e internacionais; Professor do Departamento de Turismo da Universidade Federal dos Vales do Jequitinhonha e Mucuri.
} 


\section{Introdução}

O fenômeno migratório há muito tem marcado a história brasileira. Desde o final do século XIX até meados do século XX, o país ficou caracterizado como receptor de emigrantes. No início, este movimento foi estratégia política de povoamento e serviu como angariador de mãode-obra branca especializada, em substituição à mão-de-obra escrava fartamente disponível no Brasil. Após este período, já nas décadas de 1940-50, o Brasil continuou sendo eleito como destino de pessoas de diversas nacionalidades que buscavam aqui uma vida melhor (ASSIS, 2002).

No entanto, a partir das décadas de 196070, vários brasileiros começam a emigrar, seja forçosamente, como exilados políticos do regime militar, seja como trabalhadores emigrantes temporários. Após a ditadura, na década de 1980, a emigração de brasileiros em massa para outros países se dá ao ser essa experiência considerada como projeto de melhoria de vida (ASSIS, 2002).

É importante ressaltar que a década de 1980 no Brasil foi marcada por significativas mudanças políticas, sociais e econômicas em decorrência do início do processo de abertura política, após um longo período de ditadura militar. Neste período, denominado pelos economistas como "década perdida", o país vivenciava grandes contrastes sociais e econômicos, em que a maioria da população não tinha acesso aos bens sociais básicos, como educação, saúde e habitação, tudo isso resultado de uma histórica má distribuição de renda. Este foi um longo período marcado pela "estagnação com agravamento da distribuição de renda corrente e da perda da participação dos rendimentos do trabalho na renda nacional" (LOPREATO; DEDECCA, 2013, p. 2). O Brasil ocupava um dos primeiros lugares no mundo em concentração de renda e um dos mais baixos na qualidade de vida da população (PATARRA, 2005; SILVA, 2010). Para alguns autores, a emigração foi vista por muitos como a única saída para fugir da crise econômica que assolou o País nesta década (ASSIS, 2002; GOZA, 1992; SALES, 2006).

Este movimento abrangeu também a cidade de Governador Valadares, no estado de Minas Gerais. Neste contexto, o emigrar, que inicialmente era um projeto pessoal e familiar, tornou-se um projeto compartilhado pela sociedade. Pagar as dívidas, comprar uma casa, melhorar a situação financeira - eventualmente montar um empreendimento na cidade de origem - ou conseguir um emprego, têm sido fatores propulsores desse movimento, trazendo, com o aumento do poder aquisitivo, vantagens para os envolvidos neste processo, como melhores condições de moradia, saúde, lazer e educação (SIQUEIRA, 2007). Contudo, se por um lado a emigração traz benefícios tanto para os indivíduos quanto para a sociedade na qual eles estão inseridos, por outro, pode ser entendida como criadora de obstáculos, especialmente no que tange à vida social e afetiva do emigrante $\mathrm{e}$ daqueles que o rodeiam.

\section{Teorias Econômicas das Migrações Internacionais}

Existem inúmeras teorias que explicam o fenômeno das migrações internacionais e, dentre elas, destacam-se a teoria neoclássica e a teoria histórico-estrutural, ambas caracterizadas por uma análise econômica.

$\mathrm{Na}$ perspectiva da teoria neoclássica, o indivíduo que migra avalia de forma economicamente racional as vantagens e desvantagens dos países de origem e de destino, com relação a trabalho e renda. Esse indivíduo, ao decidir inserir-se no mercado da migração global, o faz racionalmente, pois maximiza os aspectos positivos encontrados no país de destino, que geralmente possui melhores condições econômicas, constituindo-se um fator de atração; enquanto o país de origem, por não fornecer tais condições, apresenta-se para ele como um fator de 
repulsão. Dessa forma, as melhores condições de vida e de trabalho oferecidas pelo país de destino e, consequentemente, a possibilidade do aumento de renda e da realização de projetos econômicos futuros constituem-se variáveis determinantes na decisão de migrar (SIQUEIRA, 2007).

Já a teoria histórico-estrutural busca explicações das causas das migrações internacionais, principalmente nos países de destino e não nos países de origem dos fluxos migratórios. De acordo com essa perspectiva, os países desenvolvidos motivam as migrações através das condições econômicas e estruturais oferecidas ao imigrante. Duas vertentes explanam essa teoria. A primeira estabelece as análises na segmentação de mercado de trabalho, em que há uma complementação entre os imigrantes e os nativos, pois estes dois grupos atenderiam a demandas distintas do mercado de trabalho categorizados em primário e secundário. Estes mercados se diferem com relação à qualificação, salários, garantias trabalhistas e prestígio social. O mercado de trabalho primário oferece melhores condições relacionadas a estes componentes, e é neste mercado que se enquadram os nativos, diferentemente do mercado secundário ao qual se destina o imigrante. Nesse sentido, a importação do trabalho do imigrante se torna necessário ao país desenvolvido, que preenche suas vagas no mercado secundário e não precisa aumentar salários nem melhorar as condições de trabalho para atrair os nativos, o que aumentaria os custos de produção e causaria um estrangulamento no processo produtivo (SIQUEIRA, 2007).

Existe também uma segunda vertente da teoria histórico-estrutural, que considera a mobilidade do capital como criadora de condições para a mobilidade do trabalho. As mudanças estruturais ocorridas a partir dos anos 1980, com a reorganização da economia mundial, ocasionaram a formação de um espaço transnacional em que a circulação de trabalhadores é mais um entre os vários fluxos, tais como capital, mercadorias, serviços e informações (SALES, 1999).
Contudo, muitas dessas teorias econômicas têm sido criticadas por serem insuficientes para explicar os fluxos migratórios. Massey (1990) afirma que:

\begin{abstract}
Embora muitas vezes a migração internacional seja relacionada a processos econômicos, como o diferencial salarial entre os dois países envolvidos num determinado fluxo migratório, tais aspectos econômicos em si não são condições necessárias nem suficientes para explicar e entender o movimento. A migração tem um caráter muito mais dinâmico do que as análises econômicas sugerem, pois ela implica em uma variedade de mecanismos socioestruturais, sendo que a mais importante e significativa é a formação de redes sociais.
\end{abstract}

\section{A Mulher "Bem Casada", a Emigração e a Solidão}

Como demonstrado, um dos fatores determinantes, que impulsionam e fazem com que muitas pessoas migrem para o exterior é o desejo de melhorar suas condições financeiras. Aqueles que partem o fazem com o intuito de ingressar no exterior, trabalhar em empregos ou subempregos. O objetivo é a obtenção de salários superiores àqueles recebidos em seu próprio país. De acordo com os brasileiros que migraram, seria impossível conseguir salários e melhores condições financeiras no Brasil, ao trabalhar em empregos equivalentes no exterior. Um estudo realizado por Siqueira (2007) cita relatos de muitos que encontraram na emigração a única possibilidade para conseguir atingir seus objetivos mais facilmente e em menor tempo.

A decisão de emigrar muitas vezes implica a divisão da família, em que o parceiro viaja com o intuito de, uma vez no exterior, reunir recursos financeiros suficientes para levar sua família. Porém, o que se observa é que uma vez instalado no país de destino, este compromisso acaba sendo visto como um gasto a ser evitado pelo parceiro. Pressupõe que quanto mais economizar, mais rápido poderá retornar ao seu país. Com esta medida e com as dificuldades da viagem (gastos com 
passagens, travessia da fronteira, dentre outros) o tempo necessário para o reencontro muitas vezes ultrapassa o idealizado, e a viagem, que no início foi programada para ter um breve retorno, acaba se estendendo por muitos anos, isola a família e priva tanto quem vai quanto quem fica de um convívio familiar pleno (ALMEIDA; DIAS, 2004).

Ao se analisar a família neste contexto, o que se observa é um grande impacto emocional causado pelo distanciamento de seus membros. Os filhos perdem a presença do pai, e a mulher, que almejou ter com quem dividir seus sonhos, conquistas e responsabilidades, bem como acompanhar cada passo dos filhos que juntos decidiram ter, se vê responsável por desenvolver solitariamente uma tarefa para a qual raramente está de fato preparada. Em decorrência da emigração, ela deixa de contar com seu parceiro para juntos resolverem as questões do seu dia-a-dia, bem como deve manter suspensa a vivência de sua sexualidade e afetividade. No entanto, em nome do amor que sente por seu cônjuge e filhos e em prol de melhores condições financeiras, esta firma um pacto de fidelidade com o parceiro para superarem juntos as adversidades (BOECHAT et al., 2010).

Essa situação pode tornar a mulher carente e solitária, muitas vezes incapaz de expressar seus sentimentos e necessidades, pois ser "bem-casada implica viver de acordo com o que é esperado" (MORGADO, 1986), e certamente uma mulher que "reclama de tudo" não é o que se espera de uma esposa dedicada. Embora muitas vezes encontre-se em família numerosa, ela se torna prisioneira da solidão e dificilmente encontra alguém com quem possa compartilhar sua dor (MORGADO, 1986). Esta solidão degrada tanto a saúde física quanto psíquica da mulher e pode ser mascarada pela rotina diária, pela relação formal com o meio social, pelo cuidado excessivo com o corpo e com os filhos, pelo comportamento sedentário e superalimentação, ou ainda pelas vias da somatização ou religiosidade imoderada (BOECHAT et al., 2010).
A temática da solidão e seus efeitos na vida do ser humano já vêm sendo explorados desde a antiguidade. Para alguns autores, este é um sentimento inerente ao ser humano. Tanis (2003) fala da fundamental importância da solidão e destaca-a como condição existencial do ser humano. O autor observa, no decorrer de sua obra, que esta se manifesta na cultura, na literatura, no cinema e, de uma forma muito particular, na clínica psicanalítica. Ele ainda aponta que "a solidão exprime-se em uma multiplicidade de estados" (TANIS, 2003), "múltiplas solidões" que podem ser vivenciadas de várias formas, seja no isolamento voluntário, para aqueles que buscam fonte de criatividade, liberdade ou um reencontro com o self, seja no isolamento involuntário dos exilados, dos migrantes, dos estrangeiros, ou daqueles que se sentem sós ou estranhos em sua própria terra. Morgado (1986) identifica vários tipos de solidão que podem ser agrupados em solidão produtiva e improdutiva. A primeira é necessária aos estudiosos, aos sábios, para seu próprio desenvolvimento, para a construção do seu conhecimento, pela necessidade de estar sozinho. A segunda é de certa forma imposta, similar ao caso de prisioneiros, de pessoas em isolamento.

Assim, durante toda a vida, o ser humano se depara com momentos de solidão, quer seja de forma positiva, ao proporcionar mudanças e abrir espaço para o autoquestionamento, o crescimento e o amadurecimento do indivíduo como um todo, quer seja negativa, "como estado de angústia, que visa ser superado à medida que se torna insuportável para quem o padece" (TANIS, 2003). Trata-se da solidão das relações, que causa a sensação de estar só, mesmo quando se está junto.

Este segundo tipo de solidão pode ser identificado com frequência entre as mulheres de emigrantes. Para elas, a solidão se faz sintoma, na medida em que estão submetidas a uma situação que não desejaram. Féres-Carneiro, (1998, p. 382) em um trabalho sobre o casamento contemporâneo, afirma que: 
"[...] Se por um lado, os ideais individualistas estimulam a autonomia dos cônjuges, enfatizando que o casal deve sustentar o crescimento e o desenvolvimento de cada um, por outro, surge a necessidade de vivenciar a conjugalidade, a realidade comum do casal, os desejos e projetos conjugais".

É nesta situação paradoxal que tais mulheres se encontram. Por um lado, entendem e até apoiam a necessidade de seus parceiros de emigrar, mas por outro, sentem-se sozinhas e privadas da vivência da realidade comum do casal, fator que, na maioria das vezes, alimentou o sonho de se casar e de partilhar sua vida com alguém.

No contexto da emigração, a mulher que fica em sua terra deve resignar-se à solidão. Deve, sobretudo, acreditar que a vida será melhor e, por isso, aguardar pacientemente o retorno de seu marido. A esposa adormece seu lado mulher e assume então o papel de mãe e administradora dos bens (BOECHAT et al., 2010). A mulher também sente a responsabilidade de esquecer-se de que é mulher. Matos, Dias e Almeida (2010) enfatizam que, para sua tranquilidade, a única coisa de que a mulher pode se lembrar é o fato de ser mãe e que na condição de mãe deve esperar o retorno do pai de seus filhos. Assim, como corrobora Silva (2013), muitas mulheres de emigrantes passam a dedicar-se exclusivamente ao seu lado mãe - o que muitas vezes corresponde a desempenhar a função paterna - e gerenciadora das remessas enviadas.

Diante disso, é de suma importância que se lance um olhar atento sobre a mulher adormecida por detrás de cada esposa. Esposa essa que se contenta em esperar o dia em que poderá novamente viver o sonho que, de certa forma, foi o motivador de ter contraído o matrimônio. Percebe-se, assim, a relevância da promoção da reflexão sobre o sentimento de solidão fomentado pelo processo emigratório.

Nesta perspectiva, o objetivo deste trabalho é conduzir uma reflexão a respeito do sentimento de solidão que acomete mulheres cujos parceiros residem no exterior como emigrantes.

\section{Métodos e Técnicas}

Trata-se de uma pesquisa descritiva do tipo exploratória, na qual se utilizou tanto a abordagem quantitativa quanto a qualitativa. Santos (2007) afirma que a combinação das abordagens qualitativa e quantitativa pode produzir resultados de melhor qualidade e ser um meio eficiente de aumentar a compreensão do objeto de estudo.

O presente estudo apresenta um recorte de dados obtidos na Pesquisa de Survey intitulada "Impactos da emigração sobre a sexualidade da esposa do emigrante", realizada junto a 247 mulheres residentes em Governador Valadares e região. Trata-se de mulheres casadas ou que possuem algum tipo de vínculo conjugal com parceiro residente no exterior por um período mínimo de três meses, bem como aquelas que tinham marido ou parceiro fixo com sucessivos períodos de permanência no exterior com durabilidade média de um ano. Foram excluídas mulheres com algum déficit cognitivo ou que se sentiram profundamente angustiadas diante da questão em estudo, bem como aquelas que se recusaram a participar logo nos primeiros contatos para falar da possível participação na pesquisa.

A amostragem foi intencional (não probabilística). A identificação dessas mulheres se fez a partir de palestras realizadas em escolas das redes municipal, estadual e privadas do município de Governador Valadares com o tema: "Dicas para a educação dos filhos que possuem o pai no exterior", ou por indicação dessas instituições. Após cada palestra, fez-se a apresentação da pesquisa seguida do convite à participação. As mães que demonstraram interesse em participar preencheram uma lista com nome e telefone. Após agendamento do dia e horário, realizou-se a visita domiciliar para 
efetivação da entrevista, sendo os dados registrados em formulário próprio e analisados com auxílio do programa Sphinx.

A entrevista foi guiada por um Roteiro Semiestruturado de Entrevista elaborado especialmente para este estudo, contendo vinte e seis temas de discussão. As entrevistadas foram orientadas para expressarem-se livremente de acordo com suas vivências sobre os seguintes temas: 1) idade; 2) escolaridade; 3 ) estado civil; 4) tempo de relacionamento; 5) tempo de isolamento conjugal; 6) motivação para emigrar; 7) reação da mulher diante da decisão da partida do parceiro; 8) providências tomadas pelo parceiro a partir da chegada ao Exterior; 9) o sentimento diante das providências tomadas pelo parceiro; 10) atitudes tomadas pela mulher a partir do envio de remessas de dinheiro; 11) as atitudes tomadas pela mulher diante da falta do parceiro; 12) opções de lazer na ausência deste; 13) sentimentos diante de outros casais; 14) frequência anual de visitas médicas; 15) medicação utilizada pela entrevistada; 16) existência de prescrição médica; 17) sintomas apresentados; 18) tempo de uso do medicamento; 19) autoestima a partir da ida do parceiro; 20) sua avaliação sobre o distanciamento; 21) representação individual de casamento; 22) com quem a entrevistada reside; 23) religião; 24) situação quanto à libido; 25) atitudes diante do desejo sexual; 26) percepção quanto à traição feminina.

Os dados qualitativos foram apurados pela técnica da Análise do Discurso (BARDIN, 2009), com a utilização de fragmentos dos discursos das entrevistadas relacionados aos sentimentos de solidão decorrente do fato de seus parceiros residirem no exterior como emigrantes. Os dados quantitativos foram tratados estatisticamente por meio do programa SPHINX, que, além de realizar a organização dos dados, forneceu quadros e tabelas para a análise descritiva.
Este estudo foi submetido ao e aprovado pelo Comitê de Ética em Pesquisa da Universidade à qual o projeto está vinculado. Todas as participantes leram e assinaram o Termo de Consentimento Livre e Esclarecido (TCLE). O TCLE assegurou-lhes o caráter confidencial de suas respostas e o direito de não identificação, reforçando que a pesquisa possui caráter voluntário.

As mulheres que apresentaram considerável sofrimento psíquico foram encaminhadas ao Serviço de Psicologia Aplicada(SPA) da mesma universidade.

\section{Resultados}

Conforme Tabela 1, as entrevistadas possuem em média 34 anos de idade, sendo que a maior parte $(40,1 \%)$ possui entre 30 e 40 anos, seguida por aquelas com idade entre 20 e 30 anos, portanto, tratam-se de Jovens Adultas. Quanto à escolaridade, predominam aquelas que possuem o Ensino Fundamental (47,4\%) e Ensino Médio $(39,3 \%)$. Quanto ao tempo de relacionamento com o parceiro emigrado, predominam as que possuem entre 5 a 10 anos (30,3\%) e entre 10 a 15 anos $(24,7 \%)$. Embora o tempo médio de isolamento conjugal seja de 3 anos, vale atentar para o fato de que há entrevistadas cujos parceiros residem no exterior há mais de 9 anos $(6,8 \%)$. A maioria reside sozinha com os filhos $(67,5 \%)$, seguida por aquelas que retornaram para a casa dos próprios pais $(22.7 \%)$ como medida de redução de gastos. Os principais motivos que levaram seus parceiros a tomarem a decisão de emigrar foram a melhoria da situação financeira $(53,1 \%)$ e a compra de uma casa própria $(17,3 \%)$. 
Tabela 1 - Perfil das mulheres de emigrantes residentes em Governador Valadares, 2010

\begin{tabular}{|c|c|c|}
\hline \multirow{2}{*}{ Tdade } & Frequência & $\%$ \\
\hline & \multicolumn{2}{|c|}{ Tdade } \\
\hline Menos de 20 & 8 & $3,2 \%$ \\
\hline De 20 a 30 & 79 & $32,0 \%$ \\
\hline De 30 a 40 & 99 & $40,1 \%$ \\
\hline De 40 a 50 & 49 & $19,8 \%$ \\
\hline 50 e mais & 12 & $4,9 \%$ \\
\hline Total & 247 & $100,0 \%$ \\
\hline \multicolumn{3}{|l|}{ Escolaridade } \\
\hline Sem Escolaridade & 10 & $4,0 \%$ \\
\hline Ensino Fundamental & 117 & $47,4 \%$ \\
\hline Ensino Médio & 97 & $39,3 \%$ \\
\hline Ensino Superior & 23 & $9,3 \%$ \\
\hline Total & 247 & $100,0 \%$ \\
\hline \multicolumn{3}{|l|}{ Tempo de relacionamento } \\
\hline Menos de 5 & 33 & $13,4 \%$ \\
\hline De 5 a 10 & 75 & $30,3 \%$ \\
\hline De 10 a 15 & 61 & $24,7 \%$ \\
\hline De 15 a 20 & 35 & $14,2 \%$ \\
\hline De 20 a 25 & 25 & $10,1 \%$ \\
\hline 25 e mais & 18 & $7,3 \%$ \\
\hline Total & 247 & $100,0 \%$ \\
\hline \multicolumn{3}{|l|}{ Tempo de distanciamento } \\
\hline Menos de 3 & 110 & $44,5 \%$ \\
\hline De 3 a 6 & 99 & $40,2 \%$ \\
\hline De 6 a 9 & 21 & $8,5 \%$ \\
\hline De 9 a 12 & 8 & $3,2 \%$ \\
\hline 12 e mais & 9 & $3,6 \%$ \\
\hline Total & 247 & $100,0 \%$ \\
\hline \multicolumn{3}{|l|}{ Com quem residem } \\
\hline Com os filhos & 167 & $67,5 \%$ \\
\hline Com os pais & 56 & $22,7 \%$ \\
\hline Sozinhas & 12 & $4,9 \%$ \\
\hline Com a família do marido & 12 & $4,9 \%$ \\
\hline Total & 247 & $100,0 \%$ \\
\hline
\end{tabular}

Fonte: Pesquisa de campo

Diante da decisão do parceiro de tornar-se (35,2\%); sentir-se angustiada, uma vez que não emigrante, as reações emocionais mais citadas pelas desejava tê-lo longe (22,7\%); e ficar com dúvidas, participantes (Tabela 2) foram: ser solidária com a não opinando a respeito $(11,7 \%)$. Dentre as diversas decisão do parceiro e incentivá-lo em sua escolha reações ao sentimento de solidão citadas pela 
mulher do emigrante, destacam-se: buscar apoio na religião $(26,3 \%)$; manter contatos telefônicos com o cônjuge $(23,2 \%)$; e chorar e ficar deprimida $(11,6 \%)$. Sair para se distrair, conversar com outras pessoas e visitar parentes e amigos são atividades sociais também praticadas por um bom número de entrevistadas $(27,0 \%)$.

A ausência prolongada do parceiro e a reduzida participação em atividades sociais criam condições propícias para o surgimento de sentimentos negativos nessas mulheres. Dentre estes, os que mais se destacam são: ansiedade, tristeza e impaciência (46\%); e sentirem-se inferiores, solitárias, tristes, feias e desgastadas (31,3\%). Embora a ausência do parceiro gere desconforto para a maioria, foram encontradas no grupo mulheres que experimentam sentimentos positivos por estarem distanciadas do parceiro, tais como: mais magras, bonitas e felizes $(18,6 \%)$; mais independentes e livres $(4,1 \%)$.

Tabela 2 - Reações emocionais das mulheres de emigrantes de Governador Valadares, decorrentes da ida do parceiro para o exterior como emigrante, 2010

\begin{tabular}{l|cc}
\hline \multicolumn{1}{c|}{ REAÇÕES EMOCIONAIS } & Frequência & $\mathbf{\%}$ \\
\hline Reação diante da decisão do parceiro de emigrar & & \\
Foi solidária com sua decisão e o incentivou & 87 & $35,2 \%$ \\
Ficou angustiada, pois não desejava ficar longe & 56 & $22,7 \%$ \\
Ficou com dúvidas e não deu opinião & 29 & $11,7 \%$ \\
Ficou feliz por achar que a vida melhoraria & 25 & $10,1 \%$ \\
Tentou impedir de alguma maneira & 21 & $8,5 \%$ \\
Não concordou que ele a deixasse para trás & 17 & $6,9 \%$ \\
Se sentiu aliviada, pois o relacionamento não estava & 12 & $4,9 \%$ \\
bom & $\mathbf{2 4 7}$ & $\mathbf{1 0 0 , 0} \%$ \\
Total & & \\
Reaçães diante do sentimento de solidão (*) & 120 & $26,3 \%$ \\
Buscar apoio na religião & 106 & $23,2 \%$ \\
Manter contato telefônico com o cônjuge & 53 & $11,6 \%$ \\
Chorar ou ficar deprimida & 52 & $11,4 \%$ \\
Sair para se distrair & 42 & $9,2 \%$ \\
Conversar com outras pessoas & 29 & $6,4 \%$ \\
Visitar parentes e amigos & 22 & $4,8 \%$ \\
Compensar na alimentação & 22 & $4,8 \%$ \\
Trabalhar & 10 & $2,2 \%$ \\
Tomar remédios & $\mathbf{4 5 6}$ & $\mathbf{1 0 0 , 0} \%$ \\
Total & & \\
Auto percepção a partir da ausência do parceiro & & \\
(*) & 282 & $46,0 \%$ \\
Mais ansiosa, irritada e impaciente & 192 & $31,3 \%$ \\
Inferior, solitária, triste, feia e desgastada & 114 & $18,6 \%$ \\
Mais magra, bonita e feliz & 25 & $4,1 \%$ \\
Mais independente e livre & $\mathbf{6 1 3}$ & $\mathbf{1 0 0 , 0 \%}$ \\
\hline Total & & \\
\hline & &
\end{tabular}

(*) Múltiplas respostas

Fonte: Pesquisa de campo

Quando questionadas sobre o que consideram atualmente como mais importante para a vida conjugal (Tabela 3), a maioria das entrevistadas $(78,9 \%)$ afirmou que é a capacidade do casal em permanecer juntos, nos bons e maus momentos. Ao refletirem sobre o atual envolvimento no processo emigratório, bem como sobre o fato de o parceiro morar no exterior, as entrevistadas revelam que aguardam ansiosamente 
seu retorno. Em linhas gerais, o posicionamento é de que estão mais interessadas em tê-los perto do que continuarem numa busca solitária pela melhoria de condições financeiras $(74,5 \%)$.

Tabela 3 - Sentimentos e expectativas das mulheres de emigrantes de Governador Valadares, em relação a vida conjugal, 2010

\begin{tabular}{l|cc}
\hline \multicolumn{1}{c|}{ SENTIMETOS E EXPECTATIVAS } & Frequência & $\%$ \\
\hline Reavaliação das prioridades conjugais & & \\
Que o casal esteja junto nos bons e maus momentos & 195 & $78,9 \%$ \\
Que o casal trabalhe para dar um futuro melhor para os filhos & 35 & $14,2 \%$ \\
Que o casal faça tudo para ter uma vida financeira estável & 17 & $6,9 \%$ \\
Total & $\mathbf{2 4 7}$ & $\mathbf{1 0 0 , 0 \%}$ \\
& & \\
Sentimentos atuais provocados pelo isolamento conjugal & & \\
Quando ele voltar ficaremos juntos, como sonhei & 68 & $27,5 \%$ \\
Seria melhor se ele desistisse e voltasse para casa & 52 & $21,1 \%$ \\
Foi bom ele ter partido, nossa vida financeira está melhorando & 48 & $19,4 \%$ \\
Prefiro ter ele perto de mim a ter muito dinheiro & 46 & $18,6 \%$ \\
Está sendo difícil, não posso falar nada, pois ele não me ouve & 18 & $7,3 \%$ \\
Penso que minha vida está melhor com ele longe & 15 & $6,1 \%$ \\
\hline Total & $\mathbf{2 4 7}$ & $\mathbf{1 0 0 , 0 \%}$ \\
\hline
\end{tabular}

Fonte: Pesquisa de campo

A análise de conteúdo realizada possibilitou identificar duas categorias distintas de respostas: mulheres que desenvolveram experiências positivas em relação ao distanciamento do esposo e aquelas que passaram por experiências negativas. Os fragmentos dos discursos das entrevistadas revelam que, para a maioria, o distanciamento provocado pela emigração internacional do parceiro trouxe mais experiências negativas do que positivas. Tais ocorrências, expressas nos discursos das entrevistadas, serão apresentadas a seguir.

Em linhas gerais, a vida social destas mulheres fica restrita ao convívio familiar ou participação em atividades religiosas. Mesmo diante das dificuldades próprias do relacionamento conjugal, tendem a considerar importante a presença dos parceiros em sua vida diária e se ressentem pelo desgaste que o distanciamento tende a acarretar.

Entrevistada no 129: "Eu gosto de festa ao lado dele, então eu prefiro não ir. Como vou chegar sozinha, eu prefiro ficar em casa. Só vou na igreja, na casa da minha mãe, da minha sogra, só " (Casada há 18 anos com 5 de isolamento).

Entrevistada no 227: “Graças a Deus nós tivemos outra chance e voltamos. Mas a ida para o Exterior não valeu muito não, valeu como experiência e mais nada, só sofrimento mesmo" (Casada há 21 anos com 2,5 de isolamento).

O sentimento de solidão é também observado mesmo quando o discurso das entrevistadas é mascarado por elementos complementares em que ela não se coloca como centro de interesse. Neste sentido, diante da impossibilidade do iminente retorno, outras formas de aproximação são solicitadas, como se pode observar a partir de discursos cujo foco é a educação dos filhos. Este se constitui em foco legítimo, uma vez que a busca pelo bem-estar da família não está alicerçada apenas nos aspectos econômicos, mas também na garantia de que os filhos possam crescer como cidadãos, pessoas bem aceitas no seio da sociedade. Para tanto, é reclamada a autoridade paterna para dirimir questões disciplinares. 
Entrevistada no 49: "Muita, muita falta, e pra questão de obediência, apesar dele ser muito pulso firme, a ausência do pai é sentida assim bem visível mesmo" (Casada há 15 anos com 5 de isolamento).

Entrevistada no 134: "Ele a vê muito pela internet até mesmo ajuda a educá-la na medida do possível" (Casada há 8 anos com 6 de isolamento).

Em função da dicotomia presença-ausência do pai, elas se mostraram preocupadas e não medem esforços para evitar qualquer chateação e dificuldades para seus filhos, geradas pelo processo emigratório. Para manter no imaginário de seus filhos a ideia do pai herói, elevar a confiança nas relações e aumentar a coesão familiar, as entrevistadas eliminam da vida de seus filhos temas relacionados a dificuldades vivenciadas pelo pai, processo instintivamente estabelecido por estas mulheres, cujo mote é reforçar a possibilidade do retorno bem sucedido.

Entrevistada no 201: "Eu evito ficar falando sobre as dificuldades que o pai deles está enfrentando lá fora. Faz dó porque já sentem a falta do pai e eu não quero causar mais danos aos meus filhos" (Casada há 18 anos com 5 de isolamento).

Entrevistada no 214: "Sempre que o pai liga e eu coloco meu filho pra conversar com ele, falar o que aconteceu na escola, no seu dia a dia. Pra não perder mesmo a relação dele com meu filho, porque tá longe, né?" (Casada há 13 anos com 3 de isolamento).

As entrevistadas que demonstraram sentimentos positivos provocados a partir da ida do parceiro para o exterior relataram se sentir mais bonitas, mais livres e felizes. Algumas associam esses sentimentos ao fato de que as relações conjugais estavam em franca decadência. A título de exemplo, vale citar dois fragmentos de discursos das entrevistadas que se encontravam nesta situação:

Entrevistada no 78: "Foi bom ele ter ido, nosso relacionamento não estava muito bom. Estamos reavaliando tudo o que vivemos juntos e vendo se vale a pena continuarmos quando ele voltar" (Casada há 7 anos com 2 de isolamento).

Entrevistada no 81: "Me senti aliviada, pois nosso relacionamento não estava bom. Estávamos a ponto de nos separar, e a ida dele acabou sendo a solução para que isso não acontecesse" (Casada há 10 anos com 3 de isolamento).

Os indícios são de que a participação do parceiro no processo emigratório contribui para evidenciar dificuldades não aparentes da vida conjugal que forçam uma tomada de posição, sobretudo pelas mulheres. Posicionamento que, neste grupo em particular, tende à reconciliação e à continuidade do projeto de família. Apesar de muitas entrevistadas reconhecerem a fragilidade do relacionamento com o parceiro, apenas três $(1,1 \%)$ preferem que ele não mais retorne para se ver livre das obrigações de esposa.

\section{Discussão}

As mulheres de emigrantes vivenciam sua afetividade de forma ambivalente. Ao mesmo tempo em que se sentem angustiadas por não desejarem ficar longe de seus parceiros, se veem diante de uma situação de dificuldades financeiras e, ainda por cima, sentem-se coagidas a desempenhar seu papel de boa esposa. Na esperança de alcançarem uma melhor qualidade de vida, são solidárias com a decisão de partir, ao mesmo tempo em que desejam um breve retorno de seus parceiros.

Scott (2010) acredita que as famílias exercem função integradora, embora "é relegada a uma importância secundária à configuração histórica das relações sociais mais amplas" (SCOTT, 2010, p. 260). Já Prado (1981) define a família como uma instituição social que apresenta aspectos positivos na condição de núcleo afetivo, de apoio e solidariedade. Para esta autora, além dos laços de sangue, cada membro possui compromissos a serem cumpridos, como aqueles existentes entre marido e mulher. 
No entanto, o que se observa nas famílias de emigrados é que, além de mudanças na economia, a participação no processo emigratório promove alterações na dinâmica familiar. As mulheres dos emigrantes deixam de contar com seus parceiros em diversas situações cotidianas e na vivência de sua conjugalidade. Elas passam a assumir responsabilidades que seriam da competência destes, ou do casal, como na educação dos filhos e aplicação do dinheiro recebido do exterior. O tempo de permanência do parceiro no país de destino muitas vezes ultrapassa as expectativas dos envolvidos, levando-as a se sentirem solitárias e carentes tanto em termos sexuais quanto afetivos (BOECHAT, et al., 2010; MATOS; DIAS; ALMEIDA, 2010).

Buscar apoio na religião e manter contato com o cônjuge por telefone são as alternativas mais frequentes encontradas por elas para fazer frente a esses sentimentos. Tal fato se dá em decorrência do controle social ao qual estão submetidas. Diante da sociedade, na condição de mulheres casadas morando sozinhas, devem se reposicionar, submetendo-se a uma nova condição social. Elas se tornam alvos de especulações por parte de vizinhos, amigos e parentes do esposo, bem como da sociedade de um modo geral, que lhes exige fidelidade para com o parceiro e comportamento ajustado. Assim, suas opções de lazer devem se restringir a atividades "socialmente aceitas", como ir à igreja, assistir a programas pela televisão ou visitar os parentes. Este rigoroso controle contribui ainda mais para que o sentimento de solidão esteja presente no cotidiano dessas mulheres, uma vez que, além do isolamento conjugal, estão também sujeitas ao isolamento social (MACHADO, 2006; MATOS; DIAS; ALMEIDA, 2010).

Este contexto no qual estão inseridas gera, ainda que de forma indesejada, uma sobrecarga emocional que pode levá-las a desenvolver um quadro de adoecimento psíquico. Tal afirmação fundamenta-se no considerável percentual de relatos de mulheres que, diante do sentimento de solidão, ficam deprimidas, compensam com a alimentação ou tomam medicamentos $(18,6 \%)$. Tais atitudes podem ser consideradas prejudiciais tanto à sua saúde física quanto psíquica (BOECHAT et al., 2010).

A situação por elas vivenciada favorece ainda o desenvolvimento de sentimentos de tristeza, ansiedade, irritabilidade, inferioridade e impaciência, como está demonstrado na tabela 2. Este dado obtido reafirma a possibilidade da ocorrência de determinadas patologias fomentadas pelo isolamento conjugal, especialmente decorrente da abstinência sexual, já que os fatores da vida sexual têm fundamental importância nas causas de doenças neuróticas (BOECHAT et al., 2010).

Siqueira e Santos (2013) constatam que muitos daqueles que deixam seu território para buscar novas formas de vida no exterior também passam por este processo de adoecimento. A pesquisa revela que "saudade $(90,2 \%)$, solidão $(85,8 \%)$, insegurança $(56,2)$, vontade de chorar $(47,4 \%)$ e medo $(41,8 \%)$ foram sentimentos e sensações vividas pelos emigrantes entrevistados durante o período de permanência no exterior" (SIQUEIRA; SANTOS, 2013, p. 141).

Embora o objetivo do "projeto emigrar" seja promover o bem-estar de todos os familiares, uma dúvida dificilmente poderá ser elucidada: até que ponto casais isolados em decorrência da emigração encontram-se aptos para entrar na via da individualização sem colocar em risco a relação conjugal?

Este questionamento se justifica, pois, mesmo que a intenção original do processo emigratório seja melhorar a qualidade de vida das famílias, questões como a afetividade que perpassam este fenômeno devem ser consideradas. As mulheres de emigrantes, inicialmente interessadas na partida do parceiro para o exterior, consideram atualmente como mais importante que o casal permaneça junto. Para elas, lidar com a situação na qual se encontram tem se tornado tarefa cada dia mais difícil. Bauman (2007) constatou que as pessoas se sentem mais fortes quando têm alguém do lado. Em busca deste 
sentimento de fortaleza, estas esposas alimentam o sonho do retorno de seus parceiros ou, então, que estes providenciem recursos financeiros para que elas possam se juntar a eles, cumprindo o legado "até que a morte os separe".

Se por um lado o distanciamento é gerador de sofrimento, por outro, este mesmo fato pode proporcionar alívio quando a relação conjugal é marcada por conflitos ou sentimentos de fracasso da vida a dois. Aqui o distanciamento é sentido como possibilidade de bem-estar, sobretudo quando o comprometimento social inibe a tomada de decisões radicais como a separação. Neste caso, a fuga do contato por telefone ou internet, o distanciamento destas mulheres em relação à família do parceiro e ao envolvimento em relações extraconjugais tendem a colocar em xeque relações fragilizadas. Mesmo assim, deve-se estar atento ao fato de que quanto maior o tempo de isolamento, maiores são as chances de a mulher se envolver sexualmente com outra pessoa. Esta ocorrência não significa necessariamente o fim da ligação afetiva com o parceiro emigrado, ou o efetivo rompimento de uma aliança. Em muitos casos, trata-se apenas de uma forma encontrada para reconquistar a confiança, a feminilidade e a autoestima há muito deixadas em segundo plano.

\section{Considerações Finais}

O fluxo emigratório traz tanto consequências positivas quanto negativas para os envolvidos. Positivas na medida em que possibilitam a realização do sonho de uma melhor condição financeira, de maior poder aquisitivo e de melhor qualidade de vida.

No entanto, tal qualidade se torna questionável no campo psicológico e afetivo. Apesar da melhora na condição financeira, a emigração traz uma conotação negativa para as famílias envolvidas. Mesmo com o incentivo de muitas mulheres na decisão dos parceiros de emigrar, após a partida e algum tempo de experiência, elas consideram como mais importante que o casal esteja junto nos bons e nos maus momentos, relatam que preferem ter o parceiro por perto a ter muito dinheiro. Vale ressaltar que, apesar de haver acertos e comprometimentos entre o casal no momento da "separação", quando a mulher se percebe sozinha passa a pensar que não foi para isso que se casou.

Essa ocorrência que afeta grande parte de valadarenses poderia ser entendida como um reflexo da deficiência regional em oferecer emprego e renda adequados ao bem-estar de sua população. Contudo, não se pode garantir que este seja de fato o motivo para a participação de inúmeros sujeitos no processo emigratório. A este fato, soma-se o desejo de muitos em melhorar suas condições financeiras ou, ainda, de manter a qualidade de vida, quando, por questões diversas, sentem que esta se encontra ameaçada. Estas e outras situações tornam a participação no processo emigratório uma condição vista como incontornável para o alcance das expectativas. Contudo, o envolvimento do sujeito neste processo, além de afetar cada indivíduo, interfere na dinâmica familiar, colocando em risco sua coesão.

\section{Referências}

ALMEIDA, A. R.; DIAS, C. A. Dificuldades afetivas e sociais vivenciadas pela mulher cujo cônjuge reside no exterior como emigrante. Revista Brasileira de Sexualidade Humana, São Paulo, v. 15, n. 2,2004

ASSIS, G. O. Estar aqui, estar lá... uma cartografia da vida entre o Brasil e os Estados Unidos. Campinas, Núcleo de Estudos de População/ UNICAMP, 2002.

BARDIN, L. Análise de conteúdo. Lisboa: Ed. 70, 2009.

BAUMAN, Z. Tempos líquidos. Rio de Janeiro: J. Zahar, 2007.

BOECHAT, C. S. et al. Impactos do isolamento conjugal sobre a rotina da mulher do emigrado. Psicologia e Estudo, Maringá, v. 15, n. 4, p. 851860,2010 
FERES-CARNEIRO, T. Casamento contemporâneo: o difícil convívio da individualidade com a conjugalidade. Psicologia: Reflexão Crítica, Porto Alegre, v. 11, n. 2, p. 379394, 1998.

GOZA, F. A imigração brasileira na América do Norte. Revista Brasileira de Estudos de População, v. 9, n. 1, p.65-81, 1992

LOPREATO, F. L. C.; DEDECCA, C. S. Os desafios de um padrão de investimento para o crescimento com redução da desigualdade no Brasil. Texto para Discussão, Campinas, n. 223, dez. 2013.

MACHADO, I. J. Laços de sangue e fluxo de dinheiro: notas sobre o parente ausente no contexto migratório transnacional Portugal/ Governador Valadares. In: REUNIÃO BRASILEIRA DE ANTROPOLOGIA, 25., 2006, Goiânia. Anais... Goiânia: UFG, 2006. p. 1-27. 1 CD-ROM.

MASSEY, D. S. The social and economic origins of immigration. The Annals of the American Academy of Political and Social Science, [s. 1], v. 510, p. 60-72, Jul. 1990.

MATOS, E. O.; DIAS, C. A.; ALMEIDA, A. R. Reflexões sobre o lugar da mulher na vida da esposa do emigrante. Diamantina: Cedeplar, 2010. Disponível em: <http://www.cedeplar. ufmg.br/seminarios/seminario_diamantina/2010/ D10A075.pdf>. Acesso em: 14 fev. 2014.

MORGADO, B. A solidão da mulher bemcasada: um estudo sobre a mulher brasileira. Rio de Janeiro: J. Olympio, 1986.

PATARRA, N. L. Movimentos migratórios internacionais recentes de/para o Brasil e políticas sociais". In: SERVIÇO PASTORAL DOS MIGRANTES. (Org.). Travessias na desordem global: Fórum Social das Migrações. São Paulo: Paulinas, 2005, p. 355-380.

PRADO, D. O que é família. São Paulo: Brasiliense, 1981.
SALES, T. Brasil, país de emigração. 2006. Disponível em: <http:/www.oriundi.net/site/oriundi. php?menu=categdet\&id=4601 >. Acesso em: 14 fev. 2014. Cortez, 1999.

- Brasileiros longe de casa. São Paulo:

SANTOS, A. R. Metodologia cientifica: a construção do conhecimento. 7. ed. Rio de Janeiro: Lamparina, 2007.

SCOTT, P. Gerações e famílias: polissemia, mudanças históricas e mobilidade. Sociedade $e$ Estado, Brasília, v. 25, n. 2, p. 251-284, 2010.

SILVA, F. C. T. Crise da ditadura militar e o processo de abertura política do Brasil. In: FERREIRA, J.; DELGADO, L. A. N. (Org.). O Brasil republicano: o tempo da ditadura: regime militar e movimentos sociais em fins do século XX. 4. ed. Rio de Janeiro: Civilização Brasileira, 2010. v. 4, p. 243-282.

SILVA, O. R. M. Rearranjos familiares do século XXI: o empoderamento da esposa e a retomada da função paterna no seio familiar do emigrante retornado. Revista de Iniciação Científica da FFC, Marília, v. 13, n. 2, p. 1-19, 2013.

SIQUEIRA, S. O sonho frustrado e o sonho realizado: as duas faces da migração para os EUA. Nuevo Mundo Mundos Nuevo, Paris, 2007. Debate. Disponível em: <http://nuevomundo.revues.org/ document5973.html>. Acesso em: 14 fev. 2014.

SIQUEIRA, S.; SANTOS, M. H. Condições de saúde do emigrante no retorno para sua terra natal. REMHU: Revista Interdisciplinar da Mobilidade Humana, Brasília, v. 21, n. 40, p. 131-150, 2013.

TANIS, B. Circuitos da solidão: entre a clínica e a cultura. São Paulo: Casa do Psicólogo, 2003.

Recebido em: 16 out. 2015 Aceito em: 15 jan. 2016. 
